\title{
COAGULATION EFFECTS ON AEROSOL DYNAMICS ALONG AN ISOTHERMAL VERTICAL FLAT PLATE
}

\author{
Chang-Bin Huang \\ Department of Mechanical Engineering, Yuan Ze University, Chung Li 320, R.O.C. \\ Cherng-Shing Lin \\ Department of Mechanical Engineering, Yuan Ze University, Chung Li 320, R.O.C., mecslin@saturn.yzu.edu.tw \\ Shih-Cheng Wang \\ Department of Mechanical Engineering, Yuan Ze University, Chung Li 320, R.O.C.
}

Follow this and additional works at: https://jmstt.ntou.edu.tw/journal

Part of the Engineering Commons

\section{Recommended Citation}

Huang, Chang-Bin; Lin, Cherng-Shing; and Wang, Shih-Cheng (2007) "COAGULATION EFFECTS ON AEROSOL DYNAMICS ALONG AN ISOTHERMAL VERTICAL FLAT PLATE," Journal of Marine Science and Technology. Vol. 15: Iss. 4 , Article 8.

DOI: $10.51400 / 2709-6998.2050$

Available at: https://jmstt.ntou.edu.tw/journal/vol15/iss4/8

This Research Article is brought to you for free and open access by Journal of Marine Science and Technology. It has been accepted for inclusion in Journal of Marine Science and Technology by an authorized editor of Journal of Marine Science and Technology. 


\title{
COAGULATION EFFECTS ON AEROSOL DYNAMICS ALONG AN ISOTHERMAL VERTICAL FLAT PLATE
}

\author{
Chang-Bin Huang*, Cherng-Shing Lin*, and Shih-Cheng Wang*
}

Key words: aerosol, coagulation, deposition, vertical plate.

\section{ABSTRACT}

Aerosol dynamic behavior in a turbulent flow field is investigated in this study. The flow field is a natural convection boundary layer flow adjacent to a heated or cooled vertical flat plate. The main computational method is based on a boundary layer type solution combining the flow field and sectional aerosol simulation. The SIMPLE alogrithm is adopted to solve the flow continuity, momentum, energy, and aerosol concentration equations. Various aerosol dynamic transport and removal mechanisms, including fluid convection, Brownian motion, gravitational settling, thermophoretic drift, and coagulation of aerosols, are considered in the simulation model. Aerosol coagulation effects on particle transport and deposition onto an isothermal vertical plate are addressed.

\section{INTRODUCTION}

Fine-particle deposition onto surfaces is a commonly observed phenomenon for any indoor environment. Deposition of particle-phase contaminants poses an indoor material hazard, including the electronic elements in a cleanroom, paintings, and other works of art. Tobacco smoke or bioaerosol lung deposits can also cause adverse health effects or allergic reactions. A thorough understanding of aerosol behavior in the indoor environment is important to predict aerosol deposition rates and minimize/eliminate pollutant exposures.

Study results of aerosol deposition onto surfaces have been applied in many engineering fields during previous decades. The combined theoretical effects of turbulence, Brownian motion, and gravitational settling on particle deposition in enclosures have been investigated by Crump and Seinfeld [4]. Nazaroff and Cass [10] predicted the aerosol deposition rates of a laminar

Paper Submitted 06/15/06, Accepted 01/10/07. Author for Correspondence: Cherng-Shing Lin. E-mail: mecslin@saturn.yzu.edu.tw

*Department of Mechanical Engineering, Yuan Ze University, Chung Li 320, R.O.C. natural convection boundary layer flow adjacent to a heated or cooled flat plate due to combined thermophoretic drift and Brownian motion. A similarity transformation was utilized to convert all governing partial differential equations into a system of ordinary differential equations. Tsai and Lin [17] and Tsai [16] also adopted the similarity transformation to investigate the aerosol deposition rates onto different plate positions in a mixed convection flow. The similarity method in general can estimate the precipitation rates for dust, soot and mist for a laminar convection flow. However, this method cannot predict the aerosol dynamics in an unsteady turbulent flow field. Additionally, several aerosol mechanisms, such as coagulation, evaporation, and chemical reactions, cannot be treated by the similarity transformation technique.

The CFD-based numerical schemes have been commonly employed to investigate the aerosol dynamics and transport problems in a turbulent flow situation. In many systems, particle transport is due to combined convection, diffusion, and external forces. Stratmann and Whitby [15] proposed an improved numerical solution and modified an existing 2D computational heat transfer and fluid flow computer code to account for the external terms of general aerosol dynamic equations. Peterson et al. [12] compared two different model approaches for the aerosol deposition on wafers and the particle concentration profile above a wafer surface. One was the boundary-layer approach, which was mathematically and computationally simple to execute; however, the applicability range of that model was limited to those cases for which suitable boundary layer approximations can be implemented. The other approach solved the governing equations numerically by finite difference techniques, which were computationally somewhat more difficult; however, a much wider physical system range can be studied.

The two primary numerical methods for solving the aerosol dynamic and transport problems are based on Eulerian formulism and Lagrangian formulation. In the Eulerian method, both the fluid carrier and the particulate phase are assumed to be continuous. A set of 
coupled equations are then derived and solved for both phases. In the Lagrangian method, the particles are treated individually when solving the particle motion equation, and the bulk properties of the particulate phase are obtained by averaging over a significant number of particles. Lu et al. [9] introduced the basic idea of a computer code based on a Lagrangian model and a method for computing particle concentration. They applied the computer code to a turbulent flow with a strong recirculation region and showed the strong dependence of particle velocity and concentration distribution on particle parameters and gravity.

Aloyan et al. [1] applied mathematical models to solve the coagulating aerosol transport in the atmosphere and compared the results with submicron concentration levels and highly dispersed aerosols measured in Bratsk during a two-week summer expedition in 1990. Pyykonen and Jokiniemi [13] constructed two CFD-based sectional computation schemes to describe the aerosol dynamics and transport. One was based on boundary layer type streamtube methodology, and the other on full Eulerian representation.

Lee et al. [8] presented an analytical solution to Brownian aerosol particle coagulation in the low Knudsen number regime to provide time evolution of particle size distribution. They showed that the Kundsen number had a significant effect on subsequent time evolution of size distribution during the coagulation process among various sizes of particles. Keller and Siegmann [7] demonstrated that aerosol coagulation must be taken into account when monitoring the aerosol particles. Cho et al. [3] studied the effects of Brownian diffusion, thermophoresis, and particle coagulation in a Falkner-Skan wedge flow. When coagulation was considered, the geometric mean particle size and its geometric standard deviation increased and particle number density decreased, compared to the case without coagulation. The deposition flux onto the plate decreased and diffusion boundary layer thickness increased along the flow direction. Huang and Lin [6] proposed a CFD model to simulate the aerosol dynamic behavior in a laminar flow flied. The main scheme was based on a boundary layer type solution of sectional aerosol simulation. To validate the model, the deposition velocity onto an isothermal vertical surface was obtained and reasonably agreed with those of Nazaroff and Cass [10], Tsai and Lin [17], and Tsai [16], except for the coarse particles deposited onto the cold plate.

An improved CFD model is developed in this paper, to determine the aerosol distribution within a concentration boundary layer and investigate the coagulation effect on the deposition velocity onto a semiinfinite isothermal vertical flat plate. The height of plate is $3 \mathrm{~m}$, and maximum temperature difference between the plate and surrounding air is $10 \mathrm{~K}$ so that the flow field along the plate transits from a laminar into a turbulent flow. The SIMPLE computational scheme is implemented to obtain the boundary layer type solution combining the flow field and sectional aerosol simulation. Various aerosol dynamic interaction and removal mechanisms, including fluid convection, Brownian motion, gravitational settling, thermophoretic drift, and coagulation of aerosols, are considered in the simulation model to describe the particle transport phenomenon adjacent to a heated or cooled vertical flat plate. In the following, the governing equations for the flow, temperature, and aerosol concentration fields with the related empirical relationships are presented. Subsequently, the results describing the effects of coagulation on the aerosol concentration and deposition velocity are discussed. The conclusion of this work is then given in the last.

\section{GOVERNING EQUATIONS}

\section{Flow and temperature field}

Flow and temperature fields are described as a system of partial differential equations that account for the conservation of mass, momentum, energy within a differential fluid element. For a two-dimensional flow field, the governing conservation equations of mass, momentum and energy with the Boussinesq approximations are

$$
\text { Mass: } \frac{\partial u}{\partial x}+\frac{\partial v}{\partial y}=0
$$

$\mathrm{X}$-momentum:

$$
\frac{\partial u}{\partial t}+u \frac{\partial u}{\partial x}+v \frac{\partial u}{\partial y}=-\frac{1}{\rho} \frac{\partial P}{\partial x}+v\left(\frac{\partial^{2} u}{\partial x^{2}}+\frac{\partial^{2} u}{\partial y^{2}}\right)
$$

Y-momentum:

$$
\begin{aligned}
\frac{\partial v}{\partial t} & +u \frac{\partial v}{\partial x}+v \frac{\partial v}{\partial y} \\
& =-\frac{1}{\rho} \frac{\partial P}{\partial y}+v\left(\frac{\partial^{2} v}{\partial x^{2}}+\frac{\partial^{2} v}{\partial y^{2}}\right)+g \beta\left(T-T_{\infty}\right)
\end{aligned}
$$

Energy: $\frac{\partial T}{\partial t}+u \frac{\partial T}{\partial x}+v \frac{\partial T}{\partial y}=\alpha\left(\frac{\partial^{2} T}{\partial x^{2}}+\frac{\partial^{2} T}{\partial y^{2}}\right)$

where $u, v$ represent the velocities of $x$ and $y$-component separately, $t$ is time, $\rho$ is fluid density, $P$ is pressure, $v$ is the kinematic viscosity of the fluid, $\beta$ is the coefficient of the thermal expansion for the fluid, $T$ is fluid 
temperature and $T_{\infty}$ is reference fluid temperature, $\mathrm{g}$ is gravitational acceleration, and $\alpha$ is the thermal diffusivity of the fluid.

\section{Aerosol concentration field}

Transport of aerosol by air masses can be considered on the basis of a realistic model that accounts for most factors influencing particle concentration distribution- turbulent diffusion, energy-momentum thermohydrodynamic balance, location of aerosol sources and particle growth due to coagulation process. The particle size distribution is approximated by a discrete number of size sections. In the sectional method, the dynamic equations are formulated and solved for each particle size bin concentration. The general dynamic equation for size bin $\mathrm{k}$ is written as

$$
\begin{gathered}
\frac{\partial C_{k}}{\partial t}+u \frac{\partial C_{k}}{\partial x}+v \frac{\partial C_{k}}{\partial y}=D_{k}\left(\frac{\partial^{2} C_{k}}{\partial x^{2}}+\frac{\partial^{2} C_{k}}{\partial y^{2}}\right) \\
-\left(\frac{\partial u_{t h k} C_{k}}{\partial x}+\frac{\partial u_{t h k} C_{k}}{\partial y}\right)-v_{g k} \frac{\partial C_{k}}{\partial y}+\left(\frac{\partial C_{k}}{\partial t}\right)_{\text {coag. }}
\end{gathered}
$$

where $C$ is particle concentration, $D$ is particle diffusion coefficient, $u_{t h}$ is the particle drift velocity due to thermophoresis, and $\left(\frac{\partial C_{k}}{\partial t}\right)_{\text {coag. }}$ is the aerosol dynamic source term due to coagulation.

The particle diffusion coefficient is given by the StokesEinstein relation from Hinds [5]:

$$
\begin{aligned}
& D_{k}=\frac{k_{B} T C_{C}}{3 \pi \mu_{g} d_{k}} \\
& C_{C}=1+\frac{\lambda}{d_{k}}\left[2.34+1.05 \exp \left(-0.39 \frac{d_{k}}{\lambda}\right)\right]
\end{aligned}
$$

where $k_{B}$ is Stefan-Boltzman constant, $\mu_{\mathrm{g}}$ is the dynamic viscosity of the gas, $C_{C}$ is slip correction factor, $d$ is particle diameter, and $\lambda$ is gas mean free path.

When a temperature gradient is established in a field, a particle in that field experiences a force in the direction of decreasing temperature. The resulting particle movement from the force is called thermophoresis. For a small particle $(d<\lambda)$, the induced thermal force is due to the greater transfer of momentum from the gas molecules on the hot side of the particle, relative to those on the cold side. The velocity of thermophoresis is given by Waldmann and Schmitt [18] as

$$
u_{t h}=\frac{-0.55 \mu \nabla T}{\rho_{g} T} \text { for } d<\lambda
$$

For large particles $(d>\lambda)$, the mechanism is more complicated because a temperature gradient is established in the particle. The thermal force is influenced by the thermal conductivity of the particle, $k_{p}$, relative to that of the air, $k_{a}$. The thermophoretic velocity for $(d>$ $\lambda$ ) is written as Brock [2]

$$
u_{t h}=\frac{-3 \mu C_{C} H \nabla T}{2 \rho_{g} T} \text { for } d>\lambda
$$

where

$$
H \cong\left(\frac{1}{1+6 \lambda / d}\right)\left(\frac{k_{a} / k_{p}+4.4 \lambda / d}{1+2 k_{a} / k_{p}+8.8 \lambda / d}\right)
$$

Coagulation is the most primary interparticle phenomenon for aerosols. Aerosol particles collide with one another, due to their relative motion and, by adhering to each other, form larger particles. The net result is a continuous decrease in number concentration coupled with an increase in particle size. Coagulation rates depend on differential particle number concentrations and on the collision frequency function $\mathrm{K}$. The collision frequency function is defined such that $K\left(d_{p 1}, d_{p 2}\right) C$ $\left(d_{p 1}\right) C\left(d_{p 2}\right)$ is the number of collisions between particles of sizes $d_{p 1}$ and $d_{p 2}$ in a unit time and a unit volume of gas. The formulation for the Brownian collision rates and frequency function for spherical particles employed over the entire particle size spectrum is given by Reist [14]

$$
\left(\frac{\partial C_{k}}{\partial t}\right)_{\text {coag. }}=\frac{1}{2} \sum_{j=1}^{k-1} K_{j(k-j)} C_{j} C_{k-j}-\sum_{j=1}^{\infty} K_{k j} C_{k} C_{j}
$$

where

$$
\begin{aligned}
& K_{j k}=2 \pi\left(d_{1}+d_{2}\right)\left(B_{1}+B_{2}\right) k T \\
& B=\frac{C_{C}}{3 \pi \mu d}
\end{aligned}
$$

The deposition velocity (normalized particle flux) is defined as the particle flux density onto the plate divided by the particle concentration outside the boundary layer.

$$
V_{d e p}=\frac{J}{C_{\infty}}=\frac{-D(d C / d x)}{C_{\infty}}
$$

where $J$ is the particle flux onto to the plate. 


\section{Numerical scheme}

The popular two-equation model is utilized to describe the turbulent flow field. According to Patankar [11], the governing equations are written in a general format as follows

$$
\frac{\partial}{\partial t}(\rho \phi)+\operatorname{div}\left(\rho \mathbf{u} \phi-\Gamma_{\phi} \operatorname{grad} \phi\right)=S_{\phi}
$$

where $\phi$ represents each variable of velocity, temperature, turbulence kinetic energy, the dissipation rate of turbulence kinetic energy, and the various size groups of aerosol concentration, etc. $\Gamma_{\phi}$ is the effective exchange coefficient for the dependent variable $\phi . S$ is the source term of each equation. The governing equations are discretized into algebraic equations by adopting the finite volume method and the SIMPLE algorithm is implemented to solve the equations.

\section{RESULTS}

The isothermal vertical plate is infinitely wide, extending from the leading edge in the direction of flow, i.e., upward for a heated plate and downward for a cooled plate. The flow system is therefore reduced to a two dimensional problem. Boundary conditions for this model are as follows:

$$
\begin{aligned}
& u(0, y)=0 \\
& v(x, 0)=v(0, y)=v(0, \infty)=0 \\
& T(x, 0)=T(\infty, y)=0 \\
& T(0, y)=T_{\text {wall }} \\
& C(x, 0)=C(\infty, y)=1 \\
& C(0, y)=0
\end{aligned}
$$

Air properties are assumed to have an atmospheric pressure of $1 \mathrm{~atm}$ and environmental temperature of $20^{\circ} \mathrm{C}$. Air density is $1.23 \mathrm{~kg} / \mathrm{m}^{3}$, and the Prandtl number, $\mathrm{Pr}$, is set to 0.72 . Particle density is $1350 \mathrm{~kg} / \mathrm{m}^{3}$ and the diffusion coefficient of each particle size is obtained from Hinds [5].

\section{Effects of coagulation on aerosol concentration field}

The vertical plate is 3 meter high, i.e., a normal indoor wall height. The plate is heated or cooled to bring out a natural convection boundary layer near the plate, and both a laminar and a turbulent flow field occur behind the leading edge. To calculate the coagulation effects on the aerosol transport and removal process within the boundary layer, the aerosol initial concentration is assumed to have a mono-distribution for each size bin from $0.1 \mu \mathrm{m}$ (small) to $2.15 \mu \mathrm{m}$ (large) particle.

The total mass concentration with and without coagulation in the calculation domain after 10 minutes is illustrated in Figure 1, and the total number concentration of each particle size bin is shown in Figure 2. It can be seen that small particles continuously collide with other particles during the aerosol transport process and fall into larger size bins. Consequently, the concen-

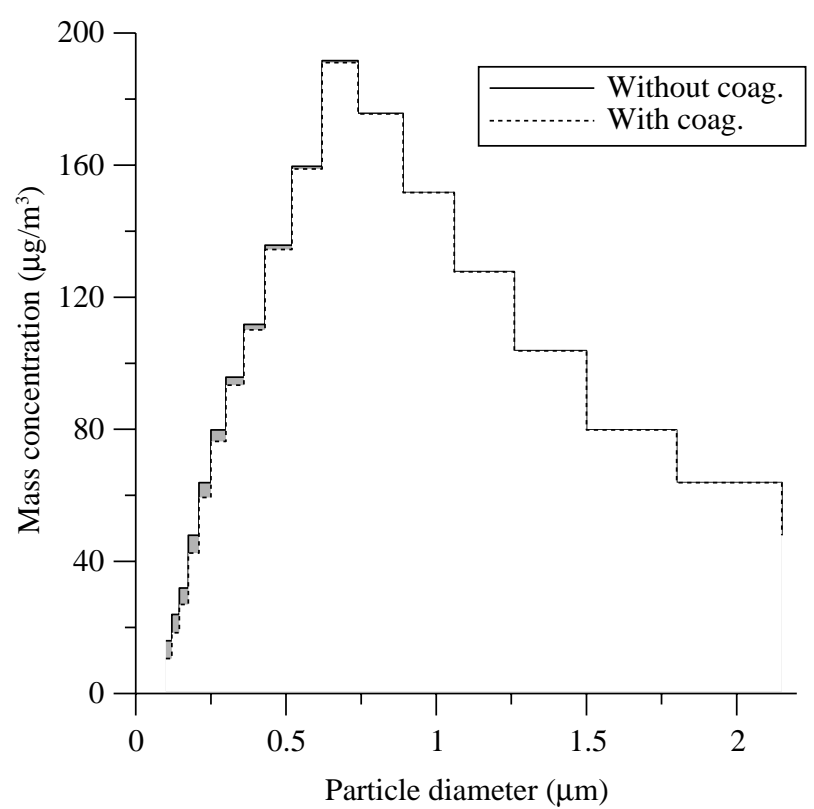

Fig. 1. The total mass concentration after $10 \mathrm{~min}$ with and without coagulation.

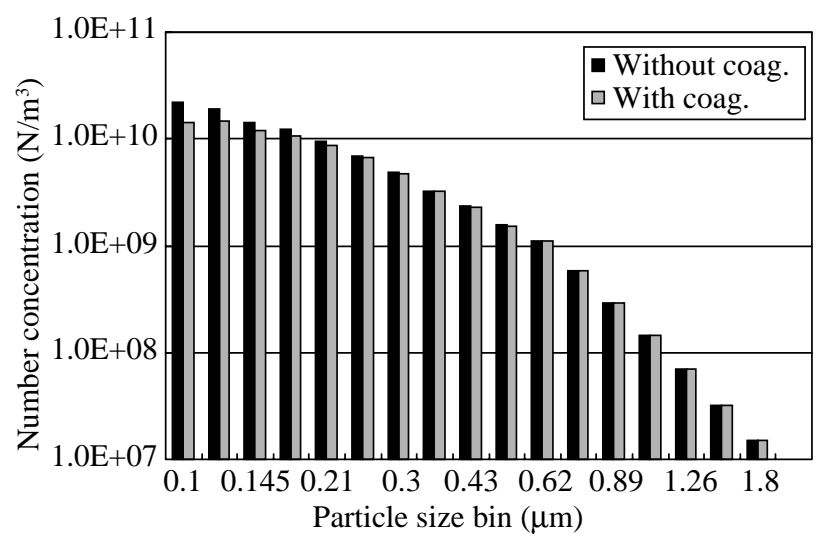

Fig. 2. The total number concentration after $10 \mathrm{~min}$ with and without coagulation. 
trations of small particle size bins decrease. However, when a large particle collides with a small particle, it is still a large particle, i.e. in the same size bin. In Figures 1 and 2, the concentrations of small particles with coagulation are obviously lower than the case without coagulation. On the contrary, the concentrations of large particle size bins with and without coagulation are virtually identical.

Figures 3 to 8 illustrate selected aerosol concentration distributions. For convenience in expressing concentration contours, the particle concentration is dimensionless and its value far from the surface is given as 1 . Figure 3 shows the $0.1 \mu \mathrm{m}$ particle concentration distributions with coagulation effect along the wall of temperature difference $+1 \mathrm{~K}$. The simulated conditions in Figure 4 are the same as in Figure 3 except neglecting the aerosol coagulation mechanism. In Figure 3, because many $0.1 \mu \mathrm{m}$ particles can collide with other particles and fall into other particle size bins, the $0.1 \mu \mathrm{m}$ particle concentration contours are uniformly distributed in the field and hence the concentration boundary layer does not exist. One the contrary, Figure 4 shows that the concentration boundary layer clearly exists in this situation. Figure 5 shows the concentration distributions of $2.15 \mu \mathrm{m}$ particles with and without coagulation. The dotted lines in Figure 5 indicate that the particle concentration contours can be greater than 1 with coagulation. However, both concentration contours are similar when the particle concentrations are below 1 .

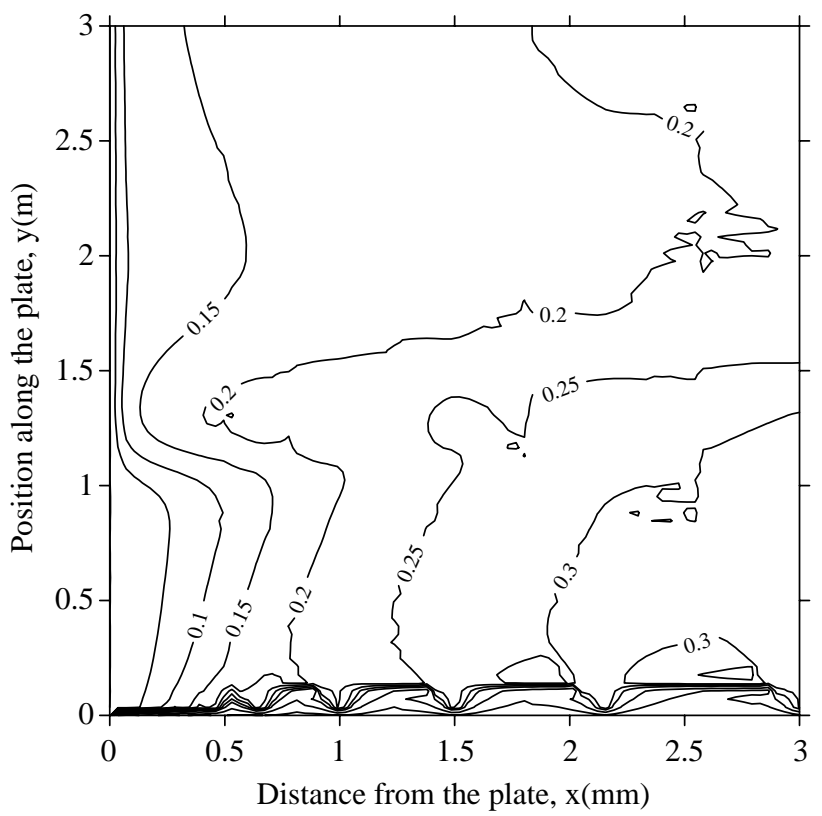

Fig. 3. 0.1 $\mu$ particle concentration distribution with coagulation along $+1 \mathrm{~K}$ vertical plate.
Figures 6 to 8 display aerosol concentration distributions along the $+10 \mathrm{~K}$ isothermal wall. Compared with Figures 3 to 5, it can be seen that the higher wall temperature difference induces higher turbulent intensity and therefore the concentration boundary layers appear to be thicker. In Figures 6 and 7, because many

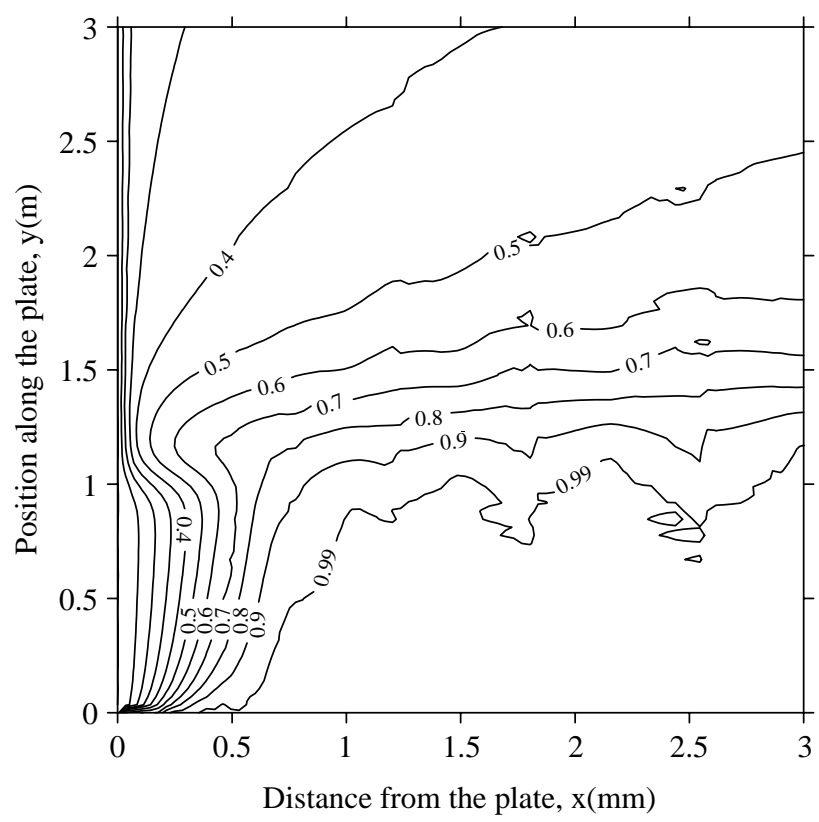

Fig. 4. 0.1 $\mu$ particle concentration distribution without coagulation along $+1 \mathrm{~K}$ vertical plate.

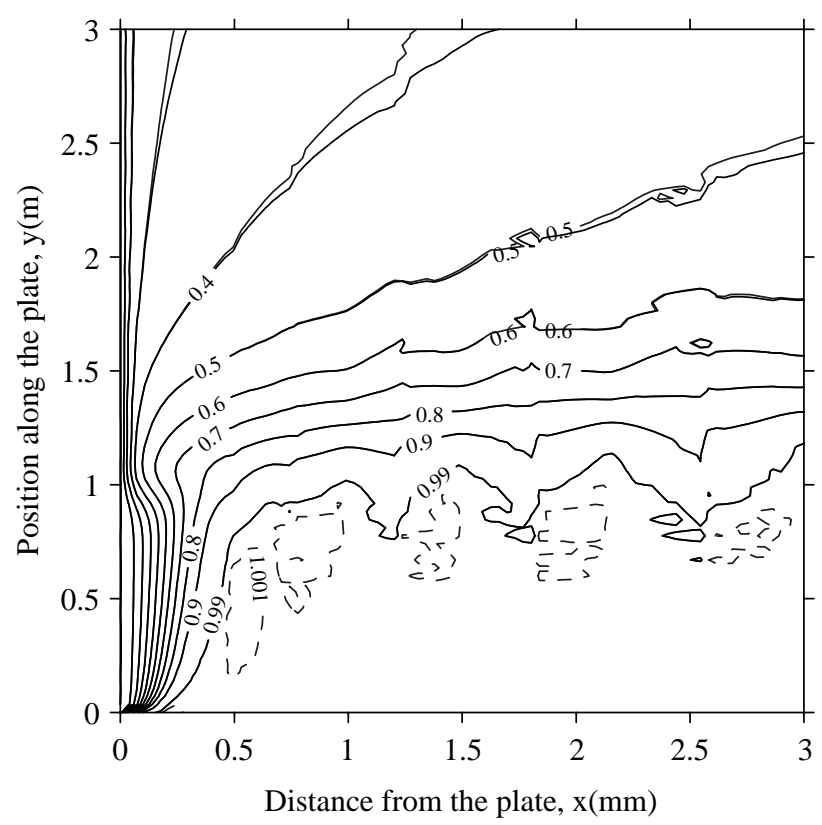

Fig. 5. 2.15 $\mu$ particle concentration distribution with and without coagulation along $+1 \mathrm{~K}$ vertical plate. 


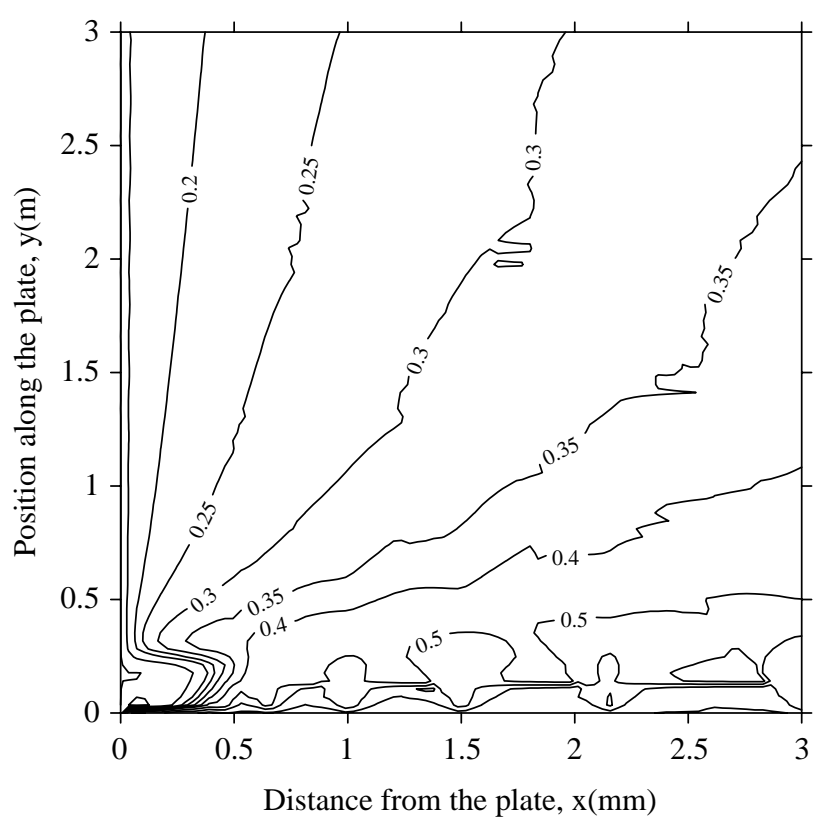

Fig. 6. $0.1 \mu$ particle concentration distribution with coagulation along $+10 \mathrm{~K}$ vertical plate.

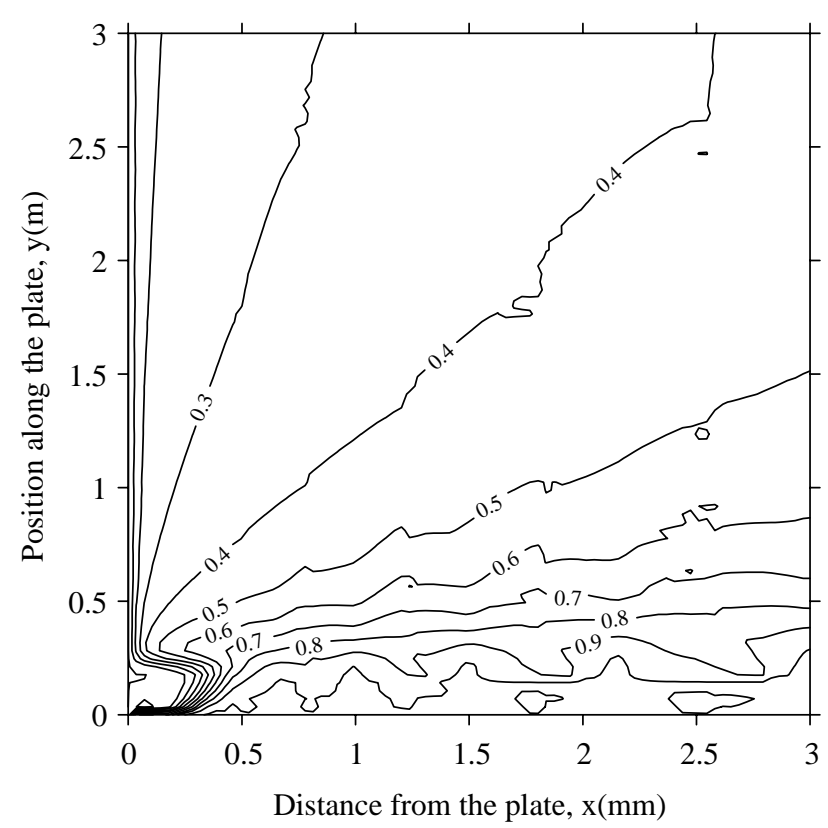

Fig. 7. $0.1 \mu$ particle concentration distribution without coagulation along $+10 K$ vertical plate.

small particles can collide with other particles (i.e., their particle concentration will be reduced), concentration contours in Figure 7 without coagulation are higher than those in Figure 6 with coagulation. As shown in Figure 8, outside the boundary layer, the concentrations are greater than 1 owing to the influence of coagulation. The concentration contours are similar in Figures 7 and

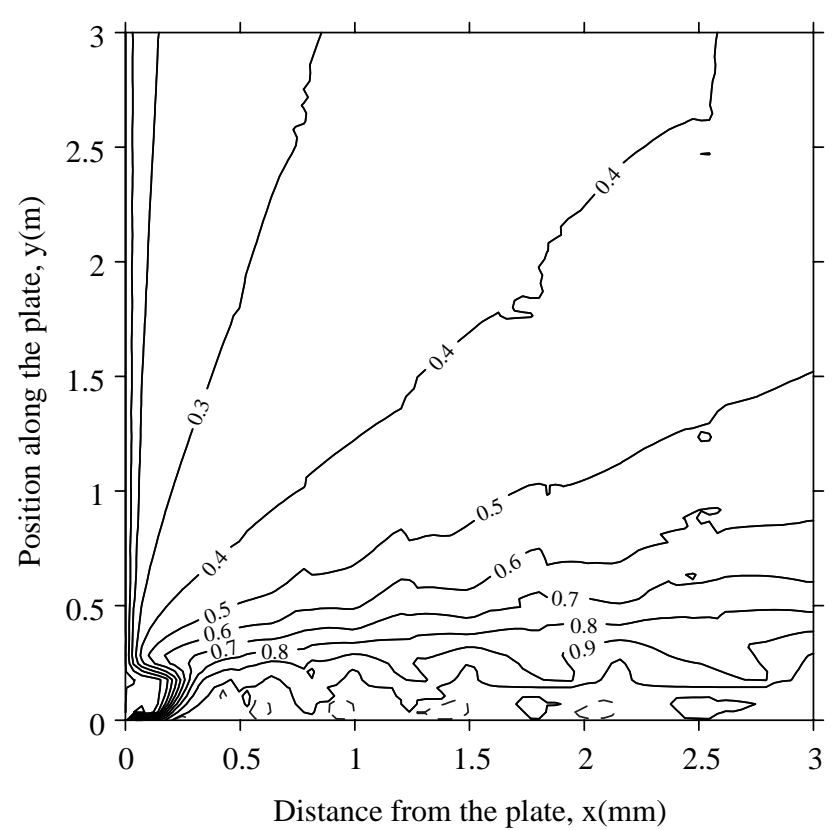

Fig. 8. 2.15 $u$ particle concentration distribution with and without coagulation along $+10 \mathrm{~K}$ vertical plate.

8 for small and large particles. This is probably because the flow field transits from a laminar into a turbulent flow regime. Turbulent intensity is dominant during the particle transport process for both small and large particles. Also noted that from Figures 5 and 8, the effect of coagulation on the concentration profiles for the large particles is practically insignificant.

\section{Effects of coagulation on aerosol deposition}

Figures 9 to 12 show the aerosol deposition velocity along a isothermal vertical plate. Here, deposition velocity is defined as the particle flux density onto the surface. Four different cases are computed to account for the effects of coagulation and temperature difference on the deposition velocity in each Figure.

The $0.1 \mu \mathrm{m}$ particle deposition velocity along a heated plate is shown in Figure 9. When the plate is warm, thermophoresis due to the temperature difference pushes particles away from the plate. The deposition velocity of $+10 \mathrm{~K}$ is lower than that of $+1 \mathrm{~K}$ early in the laminar region. Subsequently, the flow field transits from the laminar into the turbulent region. Turbulence becomes dominant and the deposition of $+10 \mathrm{~K}$ is, thus, reversely higher than that of $+1 \mathrm{~K}$. In addition, the deposition velocity with coagulation is obviously smaller than that without coagulation at the temperature difference of $+1 \mathrm{~K}$ due to the reduced particle concentration as discussed in the above section. Similar results are obtained for the case of $+10 \mathrm{~K}$. Figure 10 describes the 


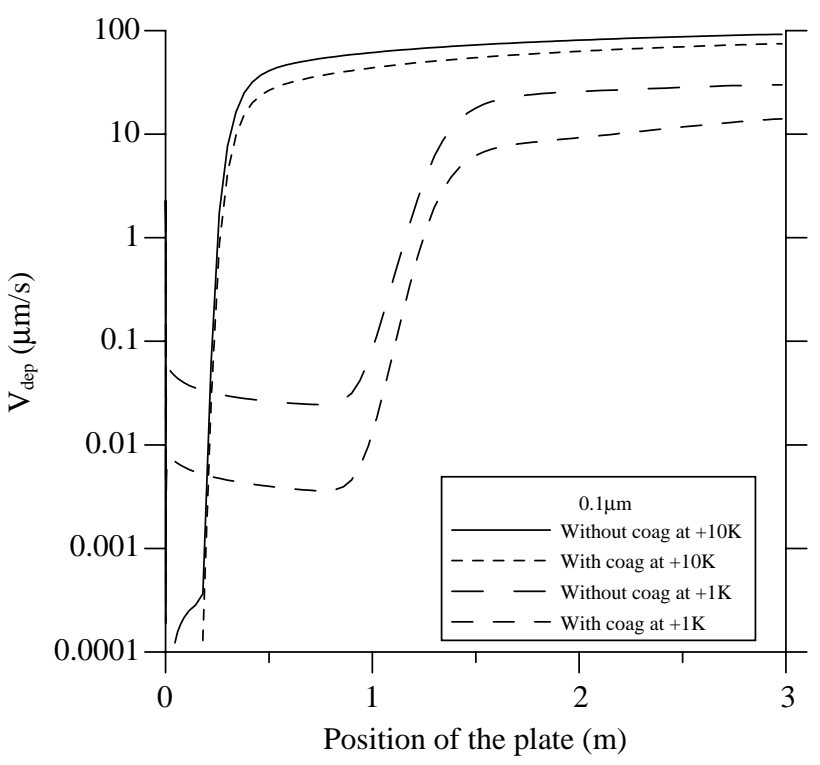

Fig. 9. 0.1 $\mu$ particle deposition velocity along a heated vertical plate.

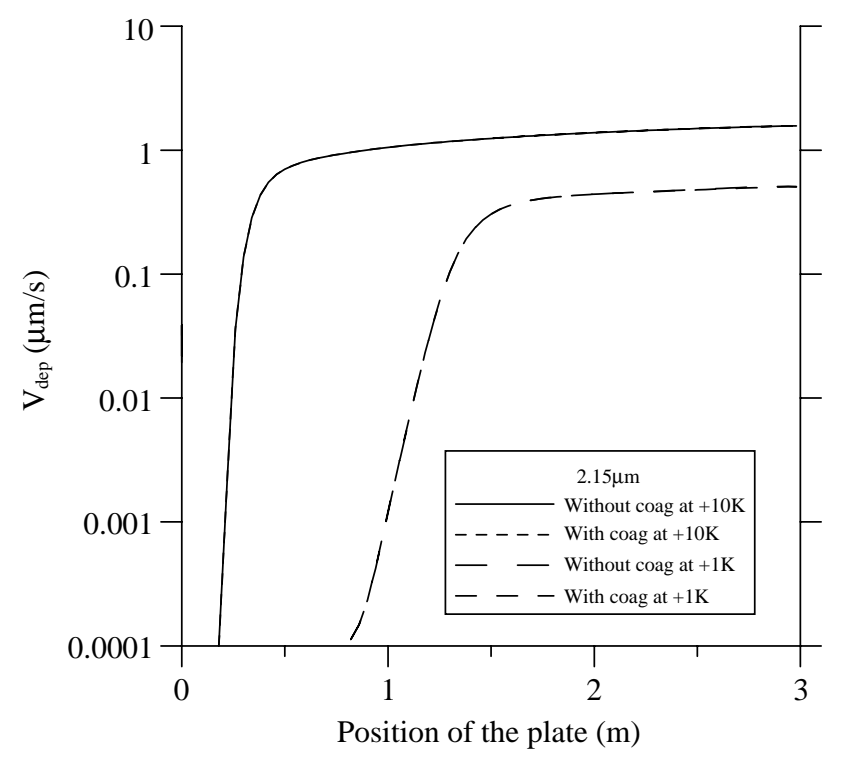

Fig. 10. $2.15 \mu$ particle deposition velocity along a heated vertical plate.

deposition velocity for the $2.15 \mu \mathrm{m}$ particle along a heated plate. The effects of thermophoresis and turbulence respectively on the deposition velocity are similar to Figure 9. However, as can be seen from Figure 10, the effect of coagulation on the deposition velocity is insignificant.

The $0.1 \mu \mathrm{m}$ particle deposition velocity along a cooled plate is illustrated in Figure 11. when the plate is cool, thermophoresis drifts particles toward the plate. The deposition velocity of $-10 \mathrm{~K}$ is higher than that of -

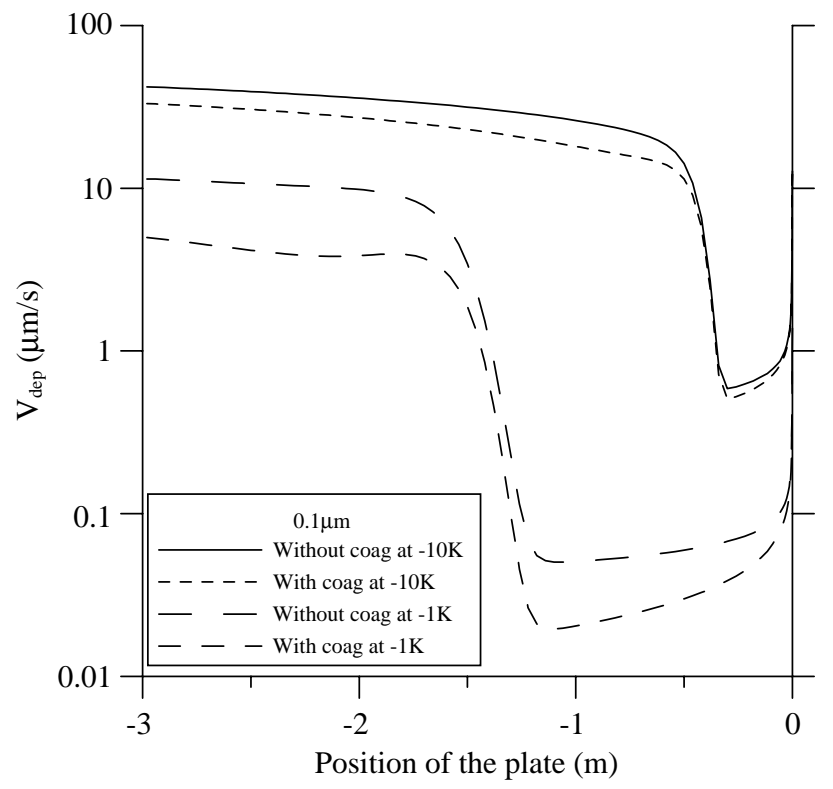

Fig. 11. 0.1 $\mu$ particle deposition velocity along a cooled vertical plate.

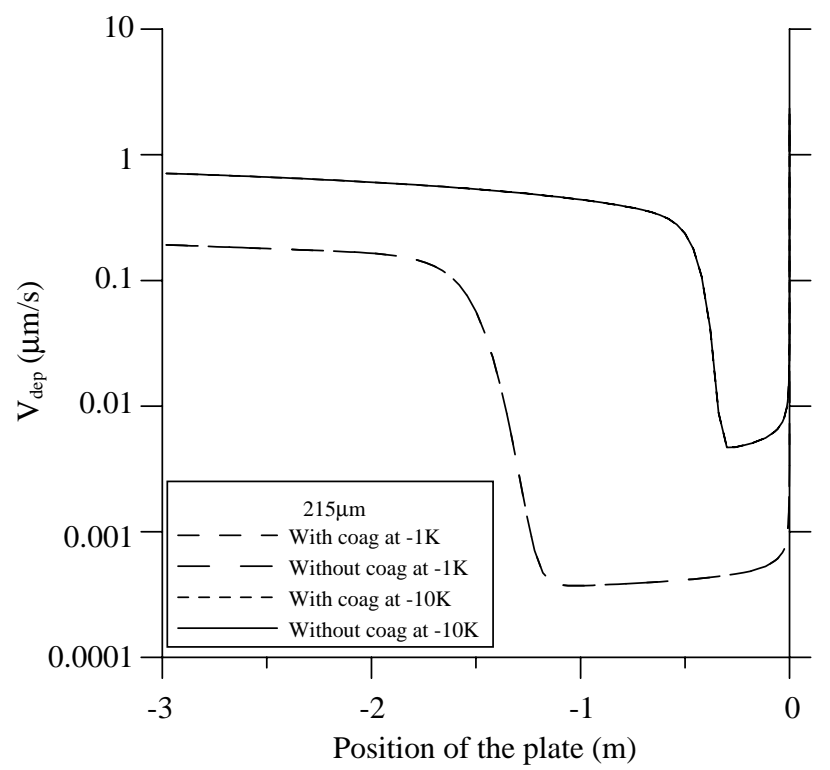

Fig. 12. 2.15 $\mu$ particle deposition velocity along a cooled vertical plate.

$1 \mathrm{~K}$ early in the laminar regime. Subsequently, when the flow field transits from the laminar into the turbulence regime, turbulence becomes dominant and, thus the deposition velocities in the regime are larger than those of in the laminar regime. The effect of coagulation on the deposition velocity is again significant similar to Figure 9. The collisions among small particle size bins reduce their concentration and hence are responsible for the smaller deposition velocity compared with the noncoagulation case. Figure 12 shows the $2.15 \mu \mathrm{m}$ deposi- 
tion velocity along a cooled plate. The effects of thermophoresis and turbulence respectively on the deposition velocity are similar to the case of the $0.1 \mu \mathrm{m}$ particle in Figure 11. Again, the effect of coagulation for the larger particles on the deposition is negligible.

\section{CONCLUSION}

An improved CFD model is developed to predict the aerosol concentration and particle deposition velocity in a turbulent flow field. Various aerosol dynamic interaction and removal mechanisms, including convection, Brownian motion, gravitational settling, thermophoresis and aerosol coagulation are considered in the simulation model to describe the particle transport phenomenon adjacent to a heated or cooled vertical plate. The SIMPLE scheme is implemented to solve the governing flow field and aerosol concentration equations. The results obtained show that the effects of coagulation on the particle concentration and deposition for the small aerosols are significant and hence, cannot be neglected in the calculation. Coagulation tends to reduce both the important parameters within the boundary layer. However, the effects of coagulation on the concentration and deposition for the large aerosols are unimportant and can be ignored. This proposed CFD model could be useful in understanding the aerosol dynamic behavior and characteristics along an isothermal vertical plate.

\section{REFERENCES}

1. Aloyan, A.E., Arutyunyan, V.O., Lushnikov, A.A., and Zagaynov, V.A., "Transport of Coagulation Aerosol in the Atmosphere," Journal of Aerosol Science, Vol. 28, pp. 67-85 (1997).

2. Brock, J.R., "On the Theory of Thermal Forces Acting on Aerosol Particles," Journal of Collide Science, Vol. 17, pp. 768-780 (1962).

3. Cho, C., Hwang, J., and Choi, M., "Deposition of Polydisperse Particles in a Falkner-Skan Wedge Flow," Journal of Aerosol Science, Vol. 27, pp. 249-261 (1996).

4. Crump, J.G. and Seinfeld, J.H., "Turbulent Deposition and Gravitational Settling of an Aerosol in a Vessel of Arbitrary shape," Journal of Aerosol Science, Vol. 12, pp. 405-415 (1981).

5. Hinds, W.C., Aerosol Technology: Properties, Behavior, and Measurement of Airborne Particles, John Wiley \& Sons, Inc., New York (1998).

6. Huang, C.B. and Lin, C.S., "Modeling of Aerosol Dynamics Along a Vertical Flat Plate," Building and Environment, Vol. 41, pp. 568-577 (2006).

7. Keller, A. and Siegmann, K., "Effects of Second Order Precesses in Aerosol Monitoring," Journal of Aerosol Science, Vol. 32, pp. 1235-1247 (2001).

8. Lee, K.W., Lee, Y.J., and Han, D.S., "The Log-Normal Size Distribution Theory for Brownian Coagulation in the Low Kundsen Number Regime," Journal of Colloid and Interface Science, Vol. 188, pp. 486-492 (1997).

9. Lu, Q.Q., Fontaine, J.R., and Aubertin, G., "Particle Motion in Two-Dimensional Confined Turbulent Flows," Aerosol Science and Technology, Vol. 17, pp. 169-185 (1992).

10. Nazaroff, W.W. and Cass, G.R., "Particle Deposition from a Natural Convention Flow onto a Vertical Isothermal Flat Plate," Journal of Aerosol Science, Vol. 18, pp. 445-455 (1987).

11. Patankar, S.V., Numerical Heat Transfer and Fluid Flow, Hemisphere Publishing Corporation. (1980).

12. Peterson, T.W., Stratmann, F., and Fissan, H., "Particle Deposition on Wafers: A Comparison between Two Modeling Approaches," Journal of Aerosol Science, Vol. 20, No. 6, pp. 483-493 (1989).

13. Pyykonen, J. and Jokiniemi, J., "Computational Fluid Dynamics Based Sectional Aerosol Modelling Schemes," Journal of Aerosol Science, Vol. 31, pp. 531-550 (2000).

14. Reist, P.C., Aerosol Science and Technology, McGrawHill, Inc., NJ (1993).

15. Stratmann, F. and Whitby, E.R., "Numerical Solution of Aerosol Dynamics for Simultaneous Convection, Diffusion and External Forces," Journal of Aerosol Science, Vol. 20, No. 4, pp. 437-440 (1989).

16. Tsai, R., "Aerosol Particle Transport in a Natural Convection Flow Onto a Vertical Flat Plate," International Journal of Heat and Mass Transfer, Vol. 44, pp. 867-870 (2001).

17. Tsai, R. and Lin, Z.Y., "An Approach for Evaluating Aerosol Particle Deposition from a Natural Convection Flow Onto a Vertical Flat Plate," Journal of Hazardous Materials, B69, pp. 217-227 (1999).

18. Waldmann, L. and Schmitt, K.H., "Thermophoresis and Diffusiophoresis of Aerosols," In Davies, C. N. (Ed.), Aerosol Science, Academic Press, London. (1966). 